\title{
Fatores prognósticos no câncer da mama feminina
}

\author{
Prognostic factors in woman breast cancer
}

\author{
Evaldo de Abreu' e Sérgio Koifman²
}

\section{Resumo}

Fatores prognósticos são parâmetros possíveis de serem mensurados no momento do diagnóstico e que servem como preditor da sobrevida do paciente. Em relação ao câncer da mama feminina tem sido elevado o número de novos fatores mencionados na literatura mundial nos últimos anos. É certo que bons planejamentos terapêuticos podem ser feitos com base no estadiamento pelo T N M , na idade, na condição menopausal e, mais recentemente, na dosagem dos receptores hormonais. A inclusão de novos fatores preditivos certamente proporciona avanços que conduzem a uma seleção ainda melhor dos pacientes principalmente para terapias adjuntivas, podendo-se mesmo chegar a uma individualização da conduta terapêutica. O s estudos originais, na sua grande maioria, analisam um conjunto de fatores em populações sempre diversas, 0 que prejudica de certa forma uma comparação entre os mesmos. A partir de uma ampla revisão de estudos originais, contemplando os mais importantes fatores prognósticos em câncer de mama, tais como tamanho do tumor, condição dos linfonodos axilares, história familiar, grau histológico, nível sócio-econômico, idade, angiogênese, catepsina D, D N A, p53, micrometástases, receptores hormonais e c-erbB-2, os autores objetivam oferecer uma avaliação atual do conhecimento dos mesmos, buscando destacar sua importância na prática clínica diária.

Palavras-chave: neoplasias mamárias; sobrevivência livre de doença; diagnóstico; receptores hormonais; prognóstico; estadiamento de neoplasias; c-erbB-2.

${ }^{1}$ M édico cancerologista. Diretor do H ospital do Câncer II do Instituto N acional deC âncer. D outorando em Saúde Pública pela Escola N acional de Saúde Pública. Enviar correspondência para E.A. Rua Clóvis Beviláqua 246 apto. 405, Tijuca; 20520-160 Rio de Janeiro, RJ - Brasil. E-mail: evaldo@inca.org.br

${ }_{2}^{2}$ M édico epidemiologista. D outor em Saúde Pública. Professor daEscola N acional de SaúdePública da Fundação 0 swaldo Cruz.

Recebido em setembro de 2001. 


\begin{abstract}
Prognostic factors are parameters measured at diagnosis enabling to forecast an affected patient's survival. Several new prognostic factors have been suggested in the literature during the last years for breast cancer. Adequate therapeutic protocols can of course be planned according to T N M staging scale, patient'sage, menopausal status, and morerecently, on hormonal receptorsquantification. Inclusion of new predictive factors in the oncological practice has allowed a better choice of specific adjuvant therapies according to the patient's profile. H owever, comparisons between different studies are usually complex, since results are obtained from different populations, thus posing some difficulties to their comparison. Following a comprehensive international literature review, we analyzed the recent contributions on the prognostic factors related to breast cancer survival, such as tumor size, lymph nodes invasion, familial antecedents of breast cancer, tumour hysthological grade, socioeconomical level, age, angiogenesis degree, bone marrow micromethastasis and molecular biomarkers such as cathepsin D, p53, hormonal receptors and c-erbB2 oncoprotein. The authors also tried to highlight their perspective use on the current clinical practice in Brazil.
\end{abstract}

Key words: breast neoplasms; disease-free survival; diagnostic; hormonal receptors; prognostic; neoplasm staging; c-erbB-2.

\section{INTRODUÇÃO}

No Brasil o câncer da mama feminina, que se constitui na patologia maligna mais incidente na população, tem o seu quadro agravado pelo fato do diagnóstico ainda ser estabelecido, na maioria das vezes, numa fase tardia da doença, em especial junto às classes com menor poder aquisitivo. $\mathrm{N}$ a grande maioria das instituições de câncer, os estadiamentos III eIV chegam a corresponder a cerca de $60 \%$ dos diagnósticos iniciais. $\mathrm{No}$ H ospital do Câncer I do Instituto $\mathrm{N}$ acional de Câncer $\left(\right.$ INCA) ${ }^{1}$ dados de 1998 apresentam 0 estadiamento III com $44,8 \%$, o IV com $16,3 \%$, enquanto apenas $6,3 \%$ tiveram 0 seu diagnóstico nos estádios 0 el.

U ma das causas no retardo do diagnóstico pode ser o reflexo da inexistência de uma política consistente de controle da doença através do diagnóstico precoce, que tem na mamografia o seu intrumento fundamental. Segundo Koch et al.2, além de insuficientes em número, os mamógrafos existentes no Brasil encontram-se mal distribuídos, estando a sua grande maioria $(76,7 \%)$ instalados em clínicas radiológicas privadas e com maior concentração nas regiões sudeste e sul do país.
O Sistema Ú nico de Saúde (SUS), responsável pela assistência médica de mais de $70 \%$ dos brasileiros, realizou no ano de 1999 o pagamento de 1.038 .341 exames mamográficos, o que corresponde a menos de $8 \%$ das mulheres maiores de 40 anos. $^{3}$

Em outros países, verifica-se também grandes diferenças em relação ao estadiamento encontrado ao diagnóstico do câncer de mama, quando comparadas classes sociais distintas. Por exemplo alguns autores ${ }^{4}$ ${ }^{6}$ têm constatado importantes diferenças no estadiamento ao compararem mulheres negras com brancas no Estados Unidos da América.

A história natural do câncer de mama indica que o curso clínico da doença e a sobrevida variam de paciente para paciente. Esta variação é determinada por uma série complexa de fatores, tais como a diferença na velocidade de duplicação tumoral, 0 potencial de metastatização do tumor e outros mecanismos, ainda não completamente compreendidos, relacionados com a condição imunológica, hormonal e nutricional do paciente ${ }^{7}$ Apesar de certos aspectos anatômicos, como o tamanho do tumor primário e as condições dos linfonodos, 
continuarem sendo fatores importantes na avaliação prognóstica, uma série de características histológicas e biológicas como grau nuclear, grau histológico e dosagem de receptores hormonais são determinantes para o prognóstico da evolução da doença.

0 conhecimento dos fatores prognósticos

é de fundamental importância na determinação dos programas terapêuticos. U ma terapia baseada em uma avaliação prognóstica possibilita a aplicação das diferentes modalidades terapêuticas utilizadas no tratamento do câncer com a intensidade e a efetividade adequadas e individualizadas para aquele paciente específico. Clark ${ }^{8}$ define três situações clínicas em que os fatores prognósticos podem ser úteis: a primeira é aquela na qual são identificados pacientes cujo prognóstico é tão bom que nenhum tratamento adjuntivo ao tratamento cirúrgico local será capaz de agregar benefício; a segunda é a identificação de pacientes que possuem um prognóstico tão pobre com 0 tratamento convencional que outras formas de tratamento mais agressivos deveriam ser instituídas; e a terceira, que é a mais proveitosa, indicaria quais pacientes serão ou não prováveis beneficiários de uma determinada terapêutica específica. 0 s fatores prognósticos permeiam um amplo universo de condições de risco, incluindo desde variáveis como a idade da paciente no momento do diagnóstico, até complexas alterações genéticas mais recentemente identificadas. A grande maioria dos novos fatores prognósticos surgidos na literatura ainda não teve comprovada a sua utilidade na prática clínica, sendo os fatores prognósticos considerados clássicos (tamanho do tumor, condição dos linfonodos axilares, tipo histológico e grau histológico) os mais correntemente utilizáveis na prática clínica oncológica.

Por outro lado, a aplicação do conhecimento sobre os fatores prognósticos pode influir favoravelmente na condução do processo terapêutico. É importante no entanto definir qual ou quais fatores, entre os muitos até agora descritos, merecem, à luz dos conhecimentos atuais, ser considerados úteis na prática diária. Diante da dificuldade em sintetizar e integrar todo esse conhecimento, vários autores têm procurado apresentar modelos preditivos, visando facilitar a apreciação prognóstica. D eve-se salientar que o importante não é a sofisticação do modelo, mas a qualidade dos dados usados para construí-los e validá-los.

N este trabalho é apresentada uma revisão da literatura recente sobre os fatores prognósticos na sobrevida do câncer da mama feminina, as implicações decorrentes de sua adequada utilização e perspectivas de seu crescente emprego no Brasil. D esta maneira, os autores buscaram aportar elementos objetivos de análise e reflexão baseados nos resultados observados na literatura recente, destinando-se aos profissionais de saúde envolvidos no cuidado das pacientes afetadas pela patologia, e assim, tentar contribuir para a compreensão dos rumos terapêuticos vivenciados atualmente nesta área da Oncologia.

\section{METODOLOGIA}

A revisão de artigos realizada adotou como critério inicial para seleção a consulta ao Index M edicus M edline (www.ncbi.nlm.nih.gov/ PubM ed) através de seu sistema de busca e utilizando as palavras-chave "breast cancer" e "prognostic factor". A opção por este banco de dados decorreu do fato de ser o mesmo uma das principais fontes de publicações científicas na atualidade, dado o rigor em seus critérios de avaliação de periódicos, incluindo contribuições originadas em periódicos com regularidade de edição e disponibilidade de conselhos científicos de avaliação dos artigos submetidos ("peer review"). A seleção procurou al cançar os artigos em língua inglesa publicados no período compreendido entre 01 de janeiro de 1986 e 31 de dezembro de 2000. Foi realizada uma leitura cuidadosa de todos os arquivos selecionados e incluídos os artigos que atenderam aos seguintes critérios: apresentaram resultados a partir de dados primários, amostra com elevado número de pacientes estudados (variação de 200 a 30.000 mulheres) e qualidade dos dados apresentados refletida através da validade estatística dos resultados 
observados. Além dos artigos selecionados a partir da busca ao M edline, também foram incluídos capítulos de livro e artigos selecionados baseados em estudos originais não restritos ao intervalo pré-estabelecido de seleção dos demais, em decorrência de seu valor como referência histórica. $\mathrm{N}$ a análise das publicações selecionadas, procedeu-se à descrição das características geográficas e demográficas da população estudada, caracterização da metodologia empregada na análise dos fatores prognósticos, o poder estatístico apresentado, a descrição da variabilidade (intervalo de confiança) dos estudos analisados e a comparabilidade dos resultados obtidos com outras investigações afins.

\section{CONCEITUAÇÃO DE FATOR PROGNÓSTICO}

U m fator prognóstico poderia ser definido como um parâmetro possível de ser mensurado no momento do diagnóstico eque serviria como preditor da sobrevida ou do tempo livre de doença. ${ }^{9}$

É constante 0 aprimoramento do conhecimento sobre fatores prognósticos, levando um grande progresso a esse campo da ciência; anualmente inúmeros estudos científicos são publicados apresentando novos fatores, muitos dos quais promissores. É certo porém que a utilização na prática diária, de sua grande maioria, seja ainda pouco factível de ser levada a efeito, mesmo em se tratando de instituições de grande porte assistencial e científico.

$\mathrm{N}$ a comparação dos resultados obtidos entre diferentes estudos de sobrevida, é essencial tomar em consideração o fato de que a coorte de pacientes acompanhada recebeu intervenção terapêutica em períodos distintos. Assim, os resultados podem estar refletindo evolução da terapêutica ao longo do tempo, e não modificações através dos fatores analisados. ${ }^{10} \mathrm{C}$ ada estratégia terapêutica se apresenta, no entanto, efetiva somente para um grupo de indivíduos, o que torna necessário o conhecimento das particularidades de cada um desses grupos, ou mesmo indivíduos.
D hingra e H ortobagyi, ${ }^{11}$ em artigo publicado em 1996, fazem uma avaliação crítica dos fatores prognósticos para 0 câncer de mama e introduzem três problemas clínicos específicos a serem superados no seu tratamento, a saber: a predição da ocorrência de micrometástases; a predição da resposta das micrometástases a um determinado tratamento; e a predição do local e momento da ocorrência da metástase. $0 \mathrm{~s}$ mesmos autores organizam os potenciais fatores prognósticos em quatro grupos, aos quais denominam geração. $\mathrm{N} \mathrm{a}$ primeira geração são agrupados os assim chamados fatores anatômicos (tamanho do tumor, comprometimento de linfonodos, subtipos histológicos, idade, etc.); na segunda geração são incluídos aqueles indicando características patológicas quantitativas (grau histológico, necrose tumoral, ploidia, índice mitótico, etc.) e responsividade endócrina (receptores hormonais de estrogênio e progesterona); na terceira geração são agrupados os fatores moleculares específicos/reguladores do crescimento (amplificadores de oncogens ex: neu/C -erbB-2, myc; e supressores de gens - ex: p53, nm23), as proteases (como a catepsina D) e outros (tais como fator de crescimento do hepatócito, glicoproteina LA.135); finalmente, na quarta geração são incluídos os preditores de metástases específicos para os diferentes órgãos (micrometástases em medula óssea, polimorfismo de L-myc, Vimentin). Os fatores apresentados como de terceira e quarta geração ainda se apresentam como grandes promessas, estando hoje a sua utilização restrita aos estudos experimentais, que buscam vencer esse grande desafio que é o desenvolvimento de marcadores prognósticos definitivos para o câncer da mama feminina.

Um dos principais objetivos contemporâneos da oncologia/mastologia é o de se identificar, quando do manuseio inicial do câncer da mama feminina, quais as pacientes que se apresentam com a maior probabilidade de serem portadoras de doença metastática microscópica. Esta identificação possibilitaria um melhor manuseio terapêutico, com uma maior seletividade na aplicação dostratamentosadjuvantes,' reduzindo 
para muitas mulheres sofrimentos oriundos dos efeitos colaterais impostos pela grande maioria dasdrogasutilizadas nos protocolos detratamento adjuvante atualmente em uso, e tão importantes para 0 aumento do intervalo livre de doença e mesmo de sua cura.

Com a evolução que vem se verificando no tratamento do câncer da mama feminina, pela introdução de diferentes esquemas terapêuticos adjuntivos, 0 potencial prognóstico de determinados fatores, como àqueles denominados por Dhingra $e$ $\mathrm{H}$ ortobaguy ${ }^{11}$ como de primeira geração, pode vir a ser modificado.

A heterogeneidade da história natural do câncer de mama é razoavelmente conhecida, porém seus determinantes ainda permanecem desconhecidos. Sendo o câncer de mama um tumor cujo desenvolvimento se processa de forma relativamente lenta, a possibilidade de se estabelecer 0 diagnóstico ainda em fase precoce é elevada. ${ }^{7} 0$ tempo médio de duplicação celular é de cerca de 100 dias, podendo, portanto, um tumor levar cerca de 8 anos para alcançar $1 \mathrm{~cm}$ de diâmetro, momento em que o diagnóstico clínico já pode ser estabelecido, através da palpação tumoral. Alguns tumores podem levar mais de 10 anos para alcançar este estágio. ${ }^{7}$

A associação entre câncer de mama localmente avançado (estadiamento III e IV do TNM - Classificação Internacional de Tumores da União Internacional Contra 0 Câncer - UICC) e mau prognóstico é um fato amplamente reconhecido.12-15

0 prognóstico de pacientes com doença localmente avançada em intervalos de 5 e 10 anos, entretanto, não é universalmente sombrio. No caso do comprometimento dos linfonodos axilares pela doença, a presença da doença metastática linfonodal geralmentereflete muito mais uma expressão do que um determinante de mau prognóstico. A presença do envolvimento axilar não significa que a evolução seja necessariamente pior do que aquela onde ele não ocorre, sendo ela simplesmente uma indicação de que o tumor da paciente pertence a um grupo de tumores biologicamente mais agressivos, sendo o grau de agressividade biológica avaliado pelo número absoluto delinfonodoscomprometidos pela doença. É, no entanto, um fato, amplamente observado, que, na sua grande maioria, as pacientes linfonodo axilares positivas apresentam uma sobrevida geral menor que a daquelas cujos linfonodos axilares não apresentam envolvimento metastático no momento da cirurgia. ${ }^{12,14,16-18}$

A variação na sobrevida entre pacientes com o mesmo estadiamento, em doença avançada, sugere que outros fatores prognósticos possam explicar algumas das diferenças verificadas na sobrevida. Inúmeros estudos, ${ }^{12-15}$ corroborando o papel de fatores ou grupo de fatores que incluem certas características demográficas (idade, raça, condição da menopausa), tumorais (tamanho do tumor, condição dos linfonodos axilares, tipo histológico), biológicas (fatores de crescimento, alteração de oncogenes, genes supressores de tumor) e outros fatores na determinação prognóstica do câncer de mama, têm sido reportados na literatura médica.

Seria aconselhável que nos estudos de sobrevida em câncer de mama fossem determinados indicadores de sobrevida global, sobrevida específica para câncer de mama, sobrevida relativa (a qual quantifica o excesso de mortalidade comparado com a da população geral), e o efeito dos fatores prognósticos tais como idadeao diagnóstico, ano do diagnóstico, condição dos linfonodos axilares, tamanho do tumor, aspectos histológicos do tumor, terapêutica aplicada, e marcadores biológicos determinados, entre outros. ${ }^{7,19} \mathrm{Q}$ uanto maior o número de fatores, maior o número de combinações possíveis, o que tem levado ao estabelecimento de índices prognósticos para câncer de mama $a^{20-22}$ que se propõem a servir de preditores da evolução e da provável recidiva dos tumores de mama.

\footnotetext{
Tratamento adjuvante (quimioterapia ou hormonioterapia adjuvantes) é um tratamento antineoplásico sistêmico cuja aplicação é iniciada logo após o tratamento primário, cirurgia ou radioterapia, e que tem por finalidade destruir os possíveis focos de micrometástases existentes e não detectáveis pelos atuais métodos diagnósticos. Já a quimioterapia neo adjuvante tem a sua indicação na redução do volume tumoral antes da cirurgia ou radioterapia e possibilita, nos casos de resposta favorável, uma abordagem cirúrgica com maiores possibilidades de controle loco-regional da doença e conseqüente aumento das chances de cura.
} 


\section{PRINCIPAIS FATORES PROGNÓSTICOS NA SOBREVIDA DO CÂNCER DA MAMA FEMININA}

Tamanho do tumor

0 tamanho do tumor juntamente com a condição dos linfonodos axilares são os dois mais importantes indicadores prognósticos para câncer de mama, tanto que se constituem na base do estadiamento TNM estabelecido e promulgado pelaUnião Internacional Contrao C âncer. ${ }^{12} \mathrm{Com}$ 0 advento da mamografia e a gradual difusão do método, associada a uma maior conscientização da população sobre sua importância, vem se observando em alguns países desenvolvidos a redução significativa no tamanho dos tumores quando do diagnóstico. $\mathrm{N}$ as três últimas décadas, a realização de cirurgias radicais (mastectomias) vem sendo reduzida gradativamente em favor das cirurgias conservadoras (segmentectomias), e um fator determinante na indicação do tratamento conservador éo tamanho do tumor no momento do diagnóstico. É certo também que o tamanho do tumor está diretamente relacionado ao risco de recidiva, sendo que, nos casos de pacientes com ausência de comprometimento metastático dos linfonodos, o tamanho do tumor tornase 0 melhor preditor desta recidiva. Se é certo que 0 tamanho do tumor éum dos mehores preditores da recidiva, é mais categórico ainda o fato de que quanto maior o seu tamanho, maiores são as chances da existência de comprometimento metastático dos linfonodos loco-regionais. 14,23,24 Estudo realizado no M emorial Sloan-Kettering Cancer Center (EUA), com 644 pacientestratados no final da década de 60 , indica uma sobrevida em 20 anos de $88 \%$, para os pacientes com tumores menores que $2 \mathrm{~cm}$. por ocasião do diagnóstico. ${ }^{25}$ Os tumores de menor tamanho estão invariavelmente relacionados a um melhor prognóstico tanto para sobrevida global quanto para sobrevida livre de doença, independente do autor, período ou tipo de tratamento aplicado (Tabela 1).
Condição dos linfonodos axilares

A presença de metástases para linfonodos axilares ocorre com grande freqüência nas pacientes com câncer de mama, mesmo nos casos com estadiamentos I e II do sistema TNM . A dissecção axilar rotineiramente realizada, ao mesmo tempo em que possibilita a remoção das metástases proporciona uma importante informação a respeito do prognóstico da doença, e conseqüentemente, possibilita uma melhor seleção no tratamento adjuvante a ser aplicado ao paciente. 0 conhecimento do envolvimento axilar e do número de linfonodos comprometidos ainda se constitui na mais importante das informações prognósticas, e inúmeros estudos demonstram que a sobrevida das pacientes está diretamente relacionada ao número de linfonodos comprometidos. ${ }^{12,14}$ Por outro lado a determinação do nível anatômico' ' dos linfonodos envolvidos pela metástase, não se constitui num preditor independente de prognóstico. ${ }^{17,26}$ Barth et al. ${ }^{17}$ concluem em seu estudo que a sobrevida dos pacientes com metástases em linfonodos do nível III émelhor predita pelo número total de linfonodos comprometidos do que pelo nível anatômico.

0 risco dos linfonodos axilares estarem comprometidos é diretamente proporcional ao tamanho do tumor. O s tumores até $1 \mathrm{~cm}$ de diâmetro apresentam a probabilidade média de 20\% a 30\% de estarem envolvidos pela doença, sendo que os tumores ductais com grau histológico elevado podem até dobrar 0 percentual de comprometimento dos linfonodos. ${ }^{12,27}$ Pacientessem comprometimento metastático para linfonodos axilares apresentam um melhor prognóstico tanto para sobrevida global quanto para sobrevida livre de doença, e acima de $77 \%$ em 10 anos de sobrevida global (Tabela2).

\section{Nível sócio-econômico \\ As classes sociais menos favorecidas são prejudicadas, pois na gran de maioria das vezes só têm o seu diagnóstico estabelecido numa}

\footnotetext{
" O s linfonodos axilares são divididos, do ponto de vista anatômico, em três níveis os quais são baseados na sua posição em relação ao músculo pequeno peitoral, a saber: nível I (nódulos no tecido lateral ou pequeno peitoral); nível II (nódulos no tecido posterior ao pequeno peitoral); e nível III (nódulos no ápice da axila).
} 
Tabela 1. Tamanho do tumor e sobrevida no câncer de mama feminina (estudos selecionados)

\begin{tabular}{|c|c|c|c|c|c|c|c|c|c|c|c|c|c|c|c|c|c|c|c|c|}
\hline \multirow[t]{2}{*}{ Investigador } & \multirow{2}{*}{$\begin{array}{l}\text { país e } \\
\text { período }\end{array}$} & \multirow[t]{2}{*}{ N } & \multirow{2}{*}{$\begin{array}{l}\text { tempo de } \\
\text { seguimento }\end{array}$} & \multirow[t]{2}{*}{ tratamento } & \multicolumn{4}{|c|}{ sobrevida ST** (\%) } & \multicolumn{4}{|c|}{ valor de p } & \multicolumn{4}{|c|}{ sobrevida SLD* (\%) } & \multicolumn{4}{|c|}{ valor de $p$} \\
\hline & & & & & $\mathrm{Tl}$ & T2 & T3 & T4 & $\mathrm{Tl}$ & T2 & $\mathrm{T} 3$ & T4 & $\mathrm{Tl}$ & $\mathrm{T} 2$ & T3 & T4 & $\mathrm{Tl}$ & T2 & T3 & T4 \\
\hline $\begin{array}{l}\text { Korzeniowski } \\
S_{[19]}\end{array}$ & \begin{tabular}{|c|} 
Polônia \\
1952-1980
\end{tabular} & 1068 & 10 anos & cirúrgico & 80 & 63 & 56 & 47 & - & $<0,15$ & $<0,006$ & $<0,0001$ & 77 & 50,5 & 42 & 30 & - & $<0,0026$ & $<0,0004$ & $<0,0001$ \\
\hline $\begin{array}{l}\text { Fentiman IS } \\
{[27]}\end{array}$ & \begin{tabular}{|c|} 
Inglaterra \\
1975-1994 \\
\end{tabular} & 336 & 10 anos? & cirúrgico & $\begin{array}{l}90_{(1)(\mathrm{A})} \\
68_{(1)(\mathrm{B})}\end{array}$ & - & - & - & $\begin{array}{l}<0,001 \\
<0,001\end{array}$ & - & - & - & $\begin{array}{l}80_{(1)} \\
65_{(2)}\end{array}$ & - & - & - & $\begin{array}{l}<0,001 \\
<0,001\end{array}$ & - & - & - \\
\hline $\begin{array}{l}\text { Salvadori B } \\
\text { [18] }\end{array}$ & $\begin{array}{c}\text { Itália } \\
\text { 1969-1970 }\end{array}$ & 743 & 10 anos & cirúrgico & $\begin{array}{l}90_{(1)} \\
77_{(2)}\end{array}$ & $\begin{array}{l}688_{(3)} \\
60_{(4)} \\
55_{(5)}\end{array}$ & 60 & - & - & - & - & - & - & - & - & - & - & - & - & - \\
\hline$\overline{\text { Adair }}_{\text {[28] }}$ & $\begin{array}{c}\text { E.U.A. } \\
\text { 1940-1943 }\end{array}$ & 1458 & 10 anos & cirúrgico & $74 \%$ & $\begin{array}{l}58_{(5)} \\
43_{(6)} \\
39_{(7)}\end{array}$ & 28 & - & - & - & - & - & - & - & - & - & - & - & - & - \\
\hline $\begin{array}{l}\text { Palmer MK } \\
\text { [23] }\end{array}$ & \begin{tabular}{|c|} 
Inglaterra \\
1970-1975 \\
\end{tabular} & 1022 & 10 anos & $\begin{array}{l}\text { cirúrgico e } \\
\text { radioterápico }\end{array}$ & $64 \%$ & 53 & - & - & - & - & - & - & - & - & - & - & - & - & - & - \\
\hline $\begin{array}{l}\text { Valagussa P } \\
\text { [24] }\end{array}$ & \begin{tabular}{|c|} 
Itália \\
1964-1968
\end{tabular} & 716 & 10 anos & $\begin{array}{c}\text { cirúrgico e } \\
\text { radioterápico }\end{array}$ & $\begin{array}{l}90,1_{(A)} \\
66,1_{(B)}\end{array}$ & $\begin{array}{l}80,1_{(A)} \\
40,8_{(B)}\end{array}$ & \begin{tabular}{|l|}
$81,3_{(A)}$ \\
$21,6_{(B)}$
\end{tabular} & - & - & - & - & - & $\begin{array}{l}80,1_{(A)} \\
50,2_{(B)}\end{array}$ & $\begin{array}{l}69,8_{(A)} \\
24, l_{(B)}\end{array}$ & $\begin{array}{l}74,9_{(A)} \\
17,6_{(B)}\end{array}$ & - & - & - & - & - \\
\hline Fischer $B_{[14]}$ & $\begin{array}{c}\text { E.U.A. } \\
\text { 1957-196? }\end{array}$ & 1048 & 5 anos & $\begin{array}{l}\text { cirúrgico + } \\
\text { qt adj x plac. }\end{array}$ & $\begin{array}{c}76_{(1)(\mathrm{A})} \\
100_{(1)(\mathrm{B})} \\
85_{(2)(\mathrm{A})} \\
67_{(2)(\mathrm{B})}\end{array}$ & $\begin{array}{l}80_{(3)(\mathrm{A})} \\
59_{(3)(\mathrm{B})} \\
69_{(4)(\mathrm{A})} \\
41_{(4)(\mathrm{B})} \\
72_{(5)(\mathrm{A})} \\
43_{(5)(\mathrm{B})}\end{array}$ & \begin{tabular}{|c|}
$74_{(9)(\mathrm{A})}$ \\
$12_{(9)(\mathrm{B})}$ \\
$75_{(10)(\mathrm{A})}$ \\
$27_{(10)(\mathrm{B})}$
\end{tabular} & - & - & - & - & - & $\begin{array}{l}93_{(1)(A)} \\
80_{(1)(B)} \\
87_{(2)(A)} \\
47_{(2)(B)}\end{array}$ & $\begin{array}{l}84_{(3)(A)} \\
49_{(3)(B)} \\
72_{(4)(A)} \\
36_{(4)(B)} \\
76_{(5)(A)} \\
32_{(5)(B)}\end{array}$ & \begin{tabular}{|c|}
$67_{(9)(A)}$ \\
$28_{(9)(B)}$ \\
$76_{(10)(A)}$ \\
$16_{(10)(B)}$
\end{tabular} & - & - & - & - & - \\
\hline Carter $\mathrm{CL}_{\text {[12] }}$ & \begin{tabular}{|c|} 
E.U.A. \\
1977-1982
\end{tabular} & 24740 & 5 anos & $\begin{array}{c}\text { não } \\
\text { informado }\end{array}$ & $\begin{array}{c}96,2_{(7)} \\
99,2_{(7)(\mathrm{A})} \\
94,9_{(8)} \\
98,3_{(8)(\mathrm{A})} \\
90,6_{(2)} \\
85,8_{(2)(\mathrm{A})}\end{array}$ & $\begin{array}{c}84,3_{(3)} \\
92,3_{(3)(\mathrm{A})} \\
77_{(4)} \\
86,2_{(4)(\mathrm{A})} \\
70,3_{(5)} \\
84,6_{(5)(\mathrm{A})} \\
\end{array}$ & $\begin{array}{c}62,7 \\
82,2_{(A)}\end{array}$ & - & - & - & - & - & - & - & - & - & - & - & - & - \\
\hline \multicolumn{2}{|c|}{ (A) Linfonodos negativos } & \multicolumn{3}{|c|}{ (2) tumor de 1 a l,9 cm } & \multicolumn{4}{|c|}{ (5) tumor de 4 a 4,9 cm } & \multicolumn{12}{|c|}{ (8) tumor de 0,5 a $0,9 \mathrm{~cm}$} \\
\hline \multicolumn{2}{|c|}{ (B) Linfonodos positivos } & \multicolumn{3}{|c|}{ (3) tumor de 2 a 2,9cm } & \multicolumn{4}{|c|}{ (6) tumor maior de $5 \mathrm{~cm}$} & \multicolumn{12}{|c|}{ (9) tumor de 5,0 a 5,9 cm } \\
\hline \multicolumn{2}{|c|}{ (1) tumor menor de $1 \mathrm{~cm}$} & \multicolumn{3}{|c|}{ (4) tumor de 3 a 3,9 cm } & (7) tumor $\mathrm{me}$ & nor de $0,5 \mathrm{~cm}$ & & & \multicolumn{12}{|c|}{ (10) tumor maior de $6 \mathrm{~cm}$} \\
\hline ** ST - sobrevid & & *SLD - S & ida livre de d & & & & & & & & & & & & & & & & & \\
\hline
\end{tabular}


Tabela 2. Compromentimento de linfonodos e sobrevida do câncer de mama feminina (estudos selecionados)

\begin{tabular}{|c|c|c|c|c|c|c|c|c|c|c|c|c|c|c|c|c|}
\hline \multirow[t]{2}{*}{ Investigador } & \multirow[t]{2}{*}{$\begin{array}{c}\text { país e } \\
\text { período }\end{array}$} & \multirow[t]{2}{*}{$\mathrm{N}$} & \multirow[t]{2}{*}{$\begin{array}{l}\text { tempo de } \\
\text { seguimento }\end{array}$} & \multirow[t]{2}{*}{ estadiamento } & \multicolumn{3}{|c|}{$\begin{array}{c}\text { sobrevida } \mathrm{ST}^{* *} \\
(\%)\end{array}$} & \multicolumn{3}{|c|}{ valor de $\mathrm{p}$} & \multicolumn{3}{|c|}{$\begin{array}{c}\text { sobrevida SLD* } \\
(\%)\end{array}$} & \multicolumn{3}{|c|}{ valor de $p$} \\
\hline & & & & & nenhum & 1 a 3 & $4 e+$ & $0 \times 1-3$ & $0 \times 4+$ & $1-3 \times 4+$ & nenhum & 1 a 3 & $4 e+$ & $0 \times 1-3$ & $0 \times 4+$ & $1-3 \times 4+$ \\
\hline $\begin{array}{l}\text { Korzeniowski } \\
\text { S [19] }\end{array}$ & $\begin{array}{c}\text { Polônia } \\
\text { 1952-1980 }\end{array}$ & 1054 & 10 anos & I, I e e III & 77 & 54 & $2 / 2$ & $<0,0001$ & $<0,0001$ & - & 68 & 9/2 & 16 & $<0,0001$ & $<0,0001$ & - \\
\hline $\begin{array}{l}\text { Valagussa P } \\
{[24]}\end{array}$ & $\begin{array}{c}\text { Itália } \\
\text { 1964-1968 }\end{array}$ & 716 & 10 anos & I, II e III & 89,1 & 53,7 & $25 / 1$ & - & - & $<0,00001$ & 72,1 & $2 / 2$ & 16,4 & - & - & $<0,00001$ \\
\hline Barth RJ [18] & $\begin{array}{c}\text { E.U.A. } \\
\text { 1979-1985 }\end{array}$ & 135 & 5 anos & |e l| & 80 & 63 & $25 / 2$ & 0,04 & $<0,0001$ & 0,006 & 83 & $13 / 3$ & 38 & - & - & - \\
\hline $\begin{array}{l}\text { Salvadori B } \\
{[18]}\end{array}$ & $\begin{array}{c}\text { Itália } \\
\text { 1969-1970 }\end{array}$ & 743 & 10 anos & I, II e III & 80 & $\begin{array}{l}68(A) \\
65(B) \\
40(C)\end{array}$ & $22 / 1$ & - & - & - & - & - & - & - & - & - \\
\hline Fisher $B$ [14] & $\begin{array}{c}\text { E.U.A. } \\
\text { 1957-196? }\end{array}$ & 1048 & 5 anos & I, II e III & - & - & - & - & - & - & 79 & $20 / 2$ & 19 & - & - & - \\
\hline Carter CL [12] & $\begin{array}{c}\text { E.U.A. } \\
\text { 1977-1982 }\end{array}$ & 24740 & 5 anos & I, I e e III & 93 & 82 & $29 / 2$ & - & - & - & - & - & - & - & - & - \\
\hline \multicolumn{2}{|l|}{ (A) 1 (um) Linfonodo } & \multicolumn{15}{|c|}{${ }^{* *}$ ST - sobrevida geral } \\
\hline \multicolumn{2}{|l|}{ (B) 2 (dois) Linfonodos } & \multirow{2}{*}{\multicolumn{15}{|c|}{ *SLD - sobrevida livre de doença }} \\
\hline (C) 3 (três) Linfonodos & & & & & & & & & & & & & & & & \\
\hline
\end{tabular}


fase avançada da doença. ${ }^{5} \mathrm{~N}$ os Estados U nidos as mulheres negras apresentaram por diversas décadas uma sobrevida de cinco anos até $17 \%$ menor que a verificada nas mulheres brancas. Q uando se buscou controlar a sobrevida pela idade, estadiamento e condições sócioeconômicas, verificou-se uma eliminação da associação, que havia sido estabelecida inicialmente, com a cor. ${ }^{4,13}$ Ainda nos Estados Unidos verificou-se que mulheres com baixa condição sócio-econômica têm menor acesso aos programas de prevenção e aos cuidados médicos, e pessoas assintomáticas desta categoria não podem fazer um bom uso dos serviços de prevenção a saúde. ${ }^{6}$ D esta maneira não há evidência de que a cor da pele per se esteja associada ao prognóstico evolutivo do câncer da mama feminina, sendo em si um indicador de acesso diferencial aos cuidados em saúde.

\section{Tipo histológico}

O carcinoma ductal infiltrante e o carcinoma lobular infiltrante, na sua apresentação pura ou em combinação com outros tipos, são as formas mais comuns de carcinoma de mama (Figura 1). Quando dois ou mais diferentes tipos de células estão presentes, 0 tumor é normalmente classificado de acordo com aquele tipo que se apresenta mais numeroso. As pacientes com carcinoma duc- tal infiltrante apresentam normalmente um maior envolvimento linfático e um pior prognóstico que aquele verificado nos pacientes com tipos menos freqüentes de carcinoma invasivo de mama. ${ }^{28,29}$

Adair et al., ${ }^{28}$ verificaram em seu estudo que a sobrevida relativa de 30 anos, para os pacientes com o sub-tipo comedocarcinoma foi duas vezes maior que a dos pacientes com carcinoma ductal infiltrante SOE ( $74 \%$ vs $33 \%$ ), assim como também os pacientes portadores dos sub-tipos papilar, medular e coloide infiltrantes apresentaram uma melhor sobrevida no longo prazo quando comparados com o carcinoma ductal infiltrante SOE. O s tumores malignos de mama do tipo carcinoma tubular ecarcinoma medular são os que apresentam o melhor prognóstico. 0 carcinoma tubular apresenta excelenteprognóstico, mesmo nas pacientes com linfonodo axilar positivo, estando a sobrevida muito próxima daquela verificada na população geral. ${ }^{30}$ Pacientes portadoras de carcinoma medular com linfonodos axilares livres de comprometimento metastático, também apresentam um bom prognóstico, com sobrevida livre de doença, em 10 anos, superior a $95 \% .^{31} \mathrm{Na}$ Tabela 3, onde são apresentados estudos comparando sobrevida entre diferentes tipos histológicos de câncer de mama, nota-se o destaque dos tumores do

\begin{tabular}{|c|c|c|}
\hline Tipo & Características Anatômicas & Características Clínicas \\
\hline Corcinomo in situ & $\begin{array}{l}\text { É um c âncer restrito ao sítio no qual se originou, não se extendendo para os tecidos } \\
\text { vizinhos. } 0 \text { termo "in situ" tem origem latina e significa "no lugar normal" }\end{array}$ & $\begin{array}{l}\text { Em geral são impal páveis, na maioria das vezes detectados pelo exame } \\
\text { mamográfico ou acidentalmente em tumorectomias por outras causas. }\end{array}$ \\
\hline $\begin{array}{l}\text { Ductal ou intra-ductal } \\
\text { tipo comedocarcinoma } \\
\text { tipo papílifero ou intra-cístico } \\
\text { tipo cribiforme } \\
\text { tipo micropapilífero } \\
\text { tipo sólido }\end{array}$ & $\begin{array}{l}\text { Microscopicamente são tumores caracterizados por ductos preenchidos com células } \\
\text { carcinomatosas arraniadas em padrão papilar, cribiforme ou sólido, com ou sem } \\
\text { necrose central. }\end{array}$ & $\begin{array}{l}\text { Representa de } 1 \text { a 3\% de todos os tumores malignos da mama. São } \\
\text { multicentricos em 33\% e bilaterais em } 10 \% \text { dos casos. }\end{array}$ \\
\hline Lobular ou intra-lobular & $\begin{array}{l}\text { Se caracteriza microscopicamente por lóbulos distendidos e preenchidos por células } \\
\text { redondas pequenas ou médias, os núcleos são uniformes e com rara atividade } \\
\text { mitótica. }\end{array}$ & $\begin{array}{l}\text { Representa de } 2 \text { a } 6 \% \text { de todos os tumores malignos da mama, é } \\
\text { comumente multicentrico, podendo ser bilateral em } 15 \text { a } 40 \% \text { dos casos. }\end{array}$ \\
\hline $\begin{array}{l}\text { Carcinomo infiltrante ou invasor } \\
\text { Ductal } \\
\text { CDI clássico ou não especificado (SOE) } \\
\text { Tubular } \\
\text { Cribiforme } \\
\text { Mucinoso } \\
\text { Medular } \\
\text { Papilífero } \\
\text { Apócrino } \\
\text { outros tipos }\end{array}$ &  & $\begin{array}{l}0 \text { mais freqüente, representa } 65 \text { a } 85 \% \text { dos tumores de mama. } 0 \text { CDI } \\
\text { clássico é o protótipo do carcinoma de mama. O tipo tubular corresponde a } \\
2 \% \text { dos tumores, é multicêntrico em } 50 \% \text { dos casos e apresenta um } \\
\text { excelente prognóstico. } 0 \text { medular em geral acomete mulheres jovens, } \\
\text { representa cerca de } 5 \% \text { dos tumores se apresenta bem circunscrito } \\
\text { podendo ser confundido com o fibroadenoma. } 0 \text { mucionoso ocorre em } \\
\text { geral na pós menopausa, representa não mais que } 2 \% \text { dos tumores da } \\
\text { mama e é bem circunscrito. } 0 \text { prognóstico é semelhante ao do tipo } \\
\text { medular cerca de } 85 \% \text { de } S G \text { em } 5 \text { anos. }\end{array}$ \\
\hline $\begin{array}{l}\text { Lobular } \\
\text { CLl cássico } \\
\text { histiocitóide } \\
\text { células em anel de sinete } \\
\text { outros tipos }\end{array}$ & $\begin{array}{l}\text { Inicia nos lóbulos, as glândulas secretores do leite, e infiltram os tecidos vizinhos. } \\
\text { Coexiste frequientemente com o lobular in situ e é a sua contrapartida infiltrante. } \\
\text { Pode ser encontrado em combinaçaco com os outros tipos. }\end{array}$ & $\begin{array}{l}\text { É o segundo mais freqüente, alcancando de } 5 \text { a 10\% dos tumores de } \\
\text { mama. Apresenta um prognóstico similar ao carcinoma ductal infiltrante. }\end{array}$ \\
\hline
\end{tabular}

Obs: O Comedocarcinoma é uma variante (tipo histológico) do carcinoma ductal infiltrante SOE. Quando ele é in situ a possibilidade de invasão do estroma é muito grande. A definição comedocarcinoma no in situ é importante pois ele é um tipo in situ de alto grau. 0 comedo é sempre grau 3 . O sólido, é um comedo sem necrose cujo grau pode variar de 1 a 3 . Nos CDIS tipo comedocarcinoma deve-se procurar
intensamente invasão do estroma, principalmente nos CDIS extensos. A progressão para CDl é mais rápida do que nos outros fipos de CDIS.

Figura 1. Classificação dos tumores epiteliais próprios da mama (adenocarcinomas) 
tipo tubular, que mesmo na presença de comprometimento metastático doslinfonodos axilares, apresentam um excelente prognóstico.

\section{Grau histológico}

0 grau histológico reflete o potencial de malignidade do tumor indicando a sua maior ou menor capacidade de metastatização. Índices prognósticos para câncer da mama feminina usando a combinação de estadiamento da doença e grau histológico são freqüentemente utilizados, podendo melhorar a predição do resultado. Seu emprego sistemático na determinação prognóstica do câncer da mama feminina, contudo, está repleto de controvérsias, devidas, principalmente, a dificuldades na sua reprodutibilidade entre diferentes patologistas e entre diferentes serviços, visto a natureza subjetiva de sua determinação. $\mathrm{H}$ á uma certa incerteza na identificação de quais são as variações morfológicas importantes a nível celular e como elas devem ser organizadas. Este problema éacrescido pelo fato do critério no sistema de graus estar baseado na habilidade de se criar subgrupos de pacientes, aproveitando as diferenças histológicas. N o decurso do processo evolutivo da doença, a verificação de desigualdades nos resultados obtidos, a partir do seguimento clínico dos pacientes, permite 0 agrupamento por características histológicas. ${ }^{32-34} \mathrm{O}$ método de gradação histológica proporciona importantes informações prognósticas e, se um protocolo baseado neste método for seguido de forma consistente, a reprodutibilidade dos resultados pode ser obtida. ${ }^{34}$

Idade

A influência da idade ao momento do diagnóstico para o prognóstico da sobrevida no câncer de mama permanece ainda controversa. ${ }^{35}$ Estes conflitos podem ter resultado do pequeno número de pacientes envolvidos nos estudos realizados, das diferenças na estratificação das idades e da falta de correção dos óbitos ocorridos por outras causas. Apesar das discordâncias apresentadas em vários estudos, existe uma certa preponderância de investigações que destacam a faixa etária de pacientes

Tabela 3. Tipo histológico e sobrevida no câncer de mama feminina (estudos selecionados)

\begin{tabular}{|c|c|c|c|c|c|c|c|c|c|}
\hline Investigador & $\begin{array}{l}\text { país e } \\
\text { período }\end{array}$ & $\mathrm{N}$ & Objetivo & $\begin{array}{c}\text { Fatores } \\
\text { analisados }\end{array}$ & $\begin{array}{c}\text { Tipo de } \\
\text { tumor }\end{array}$ & \multicolumn{2}{|c|}{ Sobrevida 10 anos } & $p$ & Conclusões \\
\hline \multirow[b]{2}{*}{$\operatorname{Diab} S G$ [30] } & \multirow[b]{2}{*}{ EUA } & \multirow[b]{2}{*}{1665} & \multirow[b]{2}{*}{$\begin{array}{c}\text { Compara sobrevida } \\
\text { do CDI (s/ especif.) } \\
\text { com carc. Tubular e } \\
\text { carc. Mucionoso }\end{array}$} & \multirow[b]{2}{*}{$\begin{array}{c}\text { RE } \\
\text { RP } \\
\text { S- phase } \\
\text { ploidia DNA } \\
\text { EGFR }\end{array}$} & \multirow[b]{2}{*}{$\begin{array}{l}\text { Tubular } \\
\text { Mucinoso }\end{array}$} & SLD & ST & \multirow[b]{2}{*}{0.001} & \multirow[b]{2}{*}{$\begin{array}{l}\text { Carc. Tubular excelente } \\
\text { prognóstico, mesmo com } \\
\text { linfonodo positivo. Sobrevida } \\
\text { próxima da população geral }\end{array}$} \\
\hline & & & & & & $94 \%$ & $\begin{array}{l}92 \% \\
81 \%\end{array}$ & & \\
\hline $\begin{array}{l}\text { Ketterhagen JP } \\
\text { [29] }\end{array}$ & $\begin{array}{c}\text { EUA } \\
1970-1971\end{array}$ & 100 & & $\begin{array}{l}\text { Grau Histológico } \\
\text { Invasão linfática } \\
\text { Trombose } \\
\text { Tamanho tumor } \\
\text { Comp. Linfonodos }\end{array}$ & $\begin{array}{l}\text { Carcinoma } \\
\text { Ductal } \\
\text { Infiltrante }\end{array}$ & $\begin{array}{l}\text { s/ critér. advers. } \\
73 \% \\
\begin{array}{l}\text { c critér. advers. } \\
33 \%\end{array}\end{array}$ & - & & $\begin{array}{l}0 \text { grau de acurácia na } \\
\text { predição da sobrevida pelos } \\
\text { fatores analisados no estudo é } \\
\text { similar ao do tamanho do } \\
\text { tumor e comprometimento dos } \\
\text { linfonodos }\end{array}$ \\
\hline Reinfus M [31] & $\begin{array}{c}\text { Polonia } \\
1952-1983\end{array}$ & 52 & $\begin{array}{c}\text { Compara o medular } \\
\text { típico, o atípico e } 0 \\
\text { não medular }\end{array}$ & $\begin{array}{c}\text { Estágio clínico } \\
\text { Tamanho tumor } \\
\text { Comp. Linfonodos } \\
\text { Compone. Intraductal }\end{array}$ & Medular & $\begin{array}{c}84,60 \% \\
N 0-97,1 \% \\
N+(1-3)-71,4 \% \\
N+(>4)-0,0 \%\end{array}$ & - & & $\begin{array}{l}0 \text { carcinoma medular é um } \\
\text { tipo histopatológico de câncer } \\
\text { de mama tem um bom } \\
\text { prognóstico principalmente nos } \\
\text { nódulos negativos. No futuro } 0 \\
\text { prognóstico dos tumores } \\
\text { medulares será muito mais } \\
\text { baseado nos parâmetros } \\
\text { moleculares e biológicos que } \\
\text { nos morfológicos }\end{array}$ \\
\hline
\end{tabular}


pertencentes a quarta e a quinta décadas da vida, como sendo a que apresenta 0 melhor prognóstico. Por outro lado, o pior prognóstico estaria reservado, ao grupo de mulheres jovens (idade igual ou inferior a 35 anos) que desenvolvem um câncer de mama, e também àquelas cujo diagnóstico venha a ser estabelecido a partir dos 75 anos de idade. ${ }^{35-38} \mathrm{~N}$ a Tabela 4, são apresentados resultados de estudos populacionais nos quais são observados os melhores resultados, para sobrevida em 5 anos, no grupo de mulheres correspondente a quarta década de vida.

0 estadiamento clínico pode atuar como um fator de tendenciosidade na interpretação da sobrevida no grupo de mulheres com idade entre 45 e 49 anos se levarmos em consideração que, na média, esse grupo de mulheres tem um diagnóstico mais precoce que aquelas dos demais grupo etários, principalmente as mais jovens e as mais velhas. Vários autores têm demonstrado que a idade tem um significativo efeito prognóstico, mesmo quando estratificado pelo estádio da doença, além do fato de queo efeito do estadiamento tende a desaparecer a partir do décimo ano de sobrevida. ${ }^{39,40} \mathrm{~N}$ a Tabela 4, são apresentado estudos de base populacional com tempo de seguimento de 5 e 10 anos, onde podemos observar uma melhor sobrevida para os pacientes na faixa etária dos 40 aos 49 anos de idade, sendo a pior verificada em menores de 30 anos de idade.
Angiogênese (densidade vascular tumoral)

A neovascularização (angiogênese) tem a sua importância no desenvolvimento do tumor e na formação de metástase há muito tempo reconhecida, sendo inicialmente constatada através de estudos experimentais realizados em animais de laboratório. ${ }^{41} \mathrm{Em}$ 1991 Weidner et al. ${ }^{42}$ apresentaram 0 primeiro estudo, no qual demonstraram a influência da neovascularização no câncer de mama feminina; a partir de então vários estudos $s^{41,43}$ vêm demonstrando a relação entre a enumeração vascular (contagem através de método manual) e a sobrevida e recidiva tumoral.

Weidner et al. ${ }^{43}$ e $\mathrm{N}$ arita et al..$^{44}$ relatam que a densidade dos microvasos é um importante fator prognóstico no carcinoma invasivo de mama, principalmente nos pacientes linfonodo-negativos estando associada com a ocorrência de metástases. Além disso, a densidade dos microvasos foi um preditor estatisticamente significativo da sobrevida entre as mulheres linfonodonegativas, tanto da sobrevida geral como da sobrevida livre de doença em todas as pacientes. ${ }^{43} \mathrm{~N}$ o futuro 0 seu uso poderá fazer parte de um painel de marcadores moleculares que servirão de base, para a programação individualizada, das decisões terapêuticas em mulheres com pequenos tumores linfonodo negativos. ${ }^{45}$

Analisando a controvérsia na relevância da angiogênese, Aceñero et al.,"${ }^{41}$ relacionam obstáculos a sua aceitação como o uso de

Tabela 4. Idade ao diagnóstico e sobrevida no câncer de mama feminina

\begin{tabular}{|c|c|c|c|c|c|c|c|c|c|c|c|c|c|c|}
\hline \multirow[t]{2}{*}{ Investigador } & \multirow{2}{*}{$\begin{array}{c}\text { país e } \\
\text { período }\end{array}$} & \multirow[t]{2}{*}{$N$} & \multirow{2}{*}{$\begin{array}{c}\text { tempo de } \\
\text { seguimento }\end{array}$} & \multirow[t]{2}{*}{ estadiamento } & \multicolumn{10}{|c|}{ sobrevida ST** (\%) } \\
\hline & & & & & $<30$ & $30-39$ & $40-44$ & $45-49$ & $50-54$ & $55-59$ & $60-64$ & $65-69$ & $70-79$ & $>80$ \\
\hline Sant $M_{\text {[38] }}$ & Finlandia & 11123 & 5 anos & todos & 73 & 77 & 79 & 82 & 78 & 74 & 75 & 73 & 70 & 66 \\
\hline Eurocare & Dinamarca & 17498 & 5 anos & todos & 71 & 75 & 77 & 76 & 73 & 70 & 70 & 68 & 64 & 51 \\
\hline Estudo & Inglaterra & 60390 & 5 anos & todos & 60 & 68 & 72 & 71 & 66 & 63 & 65 & 66 & 64 & 51 \\
\hline \multirow[t]{2}{*}{ populacional } & Escócia & 11261 & 5 anos & todos & 60 & 65 & 69 & 67 & 61 & 60 & 62 & 61 & 60 & 46 \\
\hline & $1983-1985$ & & & & & & & & & & & & & \\
\hline Host $\mathrm{H}_{[35]}$ & $\begin{array}{c}\text { Noruega } \\
1955-1980\end{array}$ & 31594 & 10 anos & todos & 47 & $\begin{array}{l}52 \\
59\end{array}$ & 60 & 66 & 64 & 55 & 50 & 53 & 54 & 52 \\
\hline Adami $H_{[39]}$ & $\begin{array}{c}\text { Suécia } \\
1960-1978\end{array}$ & 57068 & 10 anos & todos & 55.9 & $\begin{array}{l}54.2_{(A)} \\
57.2_{(B)}\end{array}$ & 63.9 & 65 & 57 & 50.9 & 52 & 52 & $\begin{array}{l}50.3_{(C)} \\
44.7_{(D)}\end{array}$ & 42.7 \\
\hline \multicolumn{2}{|l|}{ (A) 30-34 anos } & \multicolumn{13}{|c|}{ (C) $70-74$ anos $\quad{ }^{* *}$ ST - sobrevida geral } \\
\hline (B) 35-39 anos & & (D) 75 & anos & & & & & & & & & & & \\
\hline
\end{tabular}


diferentes fatores na marcação endotelial (emprego do fator VIII versus o CD 31 ou CD 34), ou a condição linfonodal dos pacientes (linfonodo positivos versus linfonodos negativos), não sendo homogêneo por sua vez o tempo de seguimento (variando de 2 a 13 anos). A avaliação da angiogênese peritumoral traduz a relação direta entre esse parâmetro e a possibilidade de metástases a distância por via hematogênica, e pode possibilitar a seleção de pacientes, com câncer inicial de mama, que necessitariam de um tratamento mais agressivo.

\section{Catepsina D}

Ravdin et al., ${ }^{46} \mathrm{em}$ um trabalho de revisão, acentuam que a catepsina $D$, pelas suas características biológicas, pode ter um papel importante no processo de invasão e de proliferação tumoral; outros estudos, no entanto, são conflitantes ao demonstrarem sua correlação com resultados clínicos. 0 s autores concluem dizendo ser a catepsina um marcador prognóstico potencialmente importante, para qual aplicações clínicas aportarão melhores definições mais adiante. Tetu et al., ${ }^{47}$ estudando 638 pacientes com linfonodos axilares positivos observaram que a significância prognóstica da catepsina $D$ pode variar de acordo com o tipo do tratamento adjuvante. Charpin et al.,48 estudando 151 pacientes tratadas com cirurgia exclusiva, não encontraram correlação em termos de sobrevida quando as mesmas não apresentavam linfonodos axilares. Billgren et al..$^{49} \mathrm{em}$ estudo recente (2000) concluiram que o papel da catepsina $D$ como indicador prognóstico é significativo e independente, podendo também ser um possível preditor do benefício do uso de tamoxifen entre os pacientes receptor de estrogênio positivo.

\section{DNA}

$D$ iferentes fatores tais como a ploidia do DN A, índice proliferativo e fração fase $S^{\prime \prime \prime}$, ou a combinação deles, tem sido estudadas para revelar a dinâmica do DNA nuclear. A parentemente há uma associação entre os índices do DNA e atividades proliferativas. $O s$ resultados indicam que os tumores com conteúdo anormal deD N A (aneuploidia), tem a fase $\mathrm{S}$ e 0 índice proliferativo elevados, e tumores com conteúdo normal de DNA (diploidia) estão associadas com baixo índice proliferativo efaseS. Keyhani-R ofagha et al., ${ }^{50}$ concluem em seu estudo existir uma forte indicação de que o conteúdo do D N A não apresenta valor prognóstico independente, e que a determinação da ploidia do D N A não é um indicador significativo de prognóstico para os tumores malignos de mama. Cufer et al. ${ }^{51}$ afirmam que as informações sobre a ploidia do D NA, obtidas a partir de material estocado, não contribuem significativamente para uma melhor diferenciação entre curta ou longa sobrevida de pacientes com câncer da mama feminina.

\section{p53}

G ene supressor de tumor e suas mutações estão relacionadas com um comportamento mais agressivo do tumor e um prognóstico desfavorável. H ou et al. ${ }^{52}$ encontram uma associação entre a expressão do p53 com receptores de estrogênio negativos e grau histológico 3. Pacientes com tumores positivos para p53 apresentaram um prognóstico pobre porém não estatisticamente significativo. Patel et al. ${ }^{53}$ encontraram a expressão aumentada do p53 associada à agressividade do tumor, recidiva ou metástase precoce e a uma sobrevida global pequena em pacientes com linfonodo axilares negativos. Poller et al., ${ }^{54}$ estudando uma série de 149 tumores primários sintomáticos, concluem que a expressão do p53 pode implicar, nos estádios iniciais, em progressão da doença. $\mathrm{H}$ arris et al., ${ }^{7}$ assinalam que as associações verificadas entre os estudos imunohistoquímicos e os resultados clínicos são promissores e nos tentam a incluir o p53 na lista de biomarcadores usados rotineiramente na tomada de decisões clínicas, porém muito precisa ser aprendido sobre a função do p53 e suas interações com outros genes e seus produtos.

\section{Micrometástases em medula óssea}

As micrometástases, ou seja a presença na medula óssea de células que reagem com anticorpo monoclonal contra antígenos tumor associados, têm sido apresentadas nos últimos anos como um novo fator prognóstico no 
câncer de mama. $M$ ansi et al., ${ }^{55}$ dizem que as micrometástases sinalizam a probabilidade de recidiva precoce e menor sobrevida em pacientes com câncer de mama. $D$ iel et al. ${ }^{56}$ colocam o aspirado de medula óssea como uma alternativa à dissecção axilar. M olino et al. ${ }^{57}$ não encontraram associação entre a positividade do aspirado e o prognóstico das pacientes. Em 1999 o mesmo autor ${ }^{58}$ conclui que não se pode excluir a possibilidade de ser a micrometástase um fator prognóstico negativo. Landys et al. ${ }^{59}$ (1998) dizem que a análise histoquímica do aspirado de medula óssea realizado pós operatoriamente pode ser um preditor útil do prognóstico em pacientes com câncer de mama estádio I e II. Braum et al. ${ }^{60}$ (1998) dizem que o método pode ser usado para aprimorar o estadiamento do tumor com conseqüências potenciais para quimioterapia adjuvante e monitoramento de resposta nos tratamentos adjuntivos. Jami et al. ${ }^{61}$ concluem que um número aumentado de micrometástases em medula óssea é um fator prognóstico independente que pode influenciar em estratégias terapêuticas futuras.

\section{Oncogene c-erbB-2}

A expressão aumentada do oncogene ${ }^{\mathrm{l}} \mathrm{C}$ erbB-2 e um mau prognóstico para as pacientes portadoras de câncer de mama foi verificada pela primeira vez em $1987 .{ }^{62}$ Esta, detectada por imuno-histoquímica (IH C), ocorre em aproximadamente $20 \%{ }^{63-66}$ detodos os cânceres de mama, e sua associação com a sobrevida global (SG) e sobrevida livre de doença (SLD ) ${ }^{62,67}$ seria devida ao aumento da atividade metastática apresentado pelas células tumorais que 0 expressam. ${ }^{63}$

U m grandenúmero de estudos, assinala que a expressão aumentada do c-erbB-2 se configura como um indicador de mau prognóstico, ${ }^{64,65,68-73}$ com os pacientes c-erbB2 apresentando um alto risco de recidiva precoce. ${ }^{68,69,72,73} \mathrm{~A}$ existência de uma correlação significativa com a condição dos linfonodos axilares, ${ }^{74-77}$ e com o grau histológico ${ }^{73,74,78}$ também tem sido demonstrada.

Com relação as metástases, sabe-se que os pacientes com expressão aumentada do cerbB-2 estão mais propensos a desenvolvêlas, observando-se, após a sua detecção, um curto período de sobrevida. ${ }^{11}$

Como preditor de resposta terapêutica seu papel é controverso, ${ }^{79}$ podendo os pacientes com a expressão aumentada do c-erbB- $2^{64,80}$ apresentar uma maior resistência às drogas quimioterápicas.

\section{Receptores hormonais}

$\mathrm{N}$ a segunda metade dos anos 70, a condição dos receptores de estrogênio (RE) e progesterona (RP) começa a ter sua significância prognóstica estabelecida. A partir da introdução do método IH C - que possibilita a utilização de tecido fixado, material de biópsia por agulha além de apresentar um custo reduzido, ${ }^{81} 0$ método ganha popularidade e é reconhecido como uma alternativa válida ${ }^{82}$ para o bioquímico (DCCA) e se universaliza.

U m aspecto ainda controverso é 0 estabelecimento do ponto de corte, ${ }^{83-88}$ ou seja, a distribuição dos valores que definem a condição de negativo ou positivo.

$O R E$, quando negativo, acha-se correlacionado com baixa diferenciação tumoral, alta taxa de proliferação celular e outras características desfavoráveis ao prognóstico das pacientes com câncer de mama, sendo a idade também um fator de correlação. ${ }^{16,89}$

Com relação à sobrevida, os pacientes com tumores RE positivos tendem a ter uma sobrevida maior que àqueles $\mathrm{RH}$ negativos. ${ }^{16,87,90-92}$ O RP tem sido apresentado, na maioria dos estudos, ${ }^{88,93-95}$ como portador de um papel secundário como preditor prognóstico no câncer de mama.

Estudos mais recentes vem demonstrando

\footnotetext{
II' U ma das fases em que o ciclo celular é convencionalmente dividido, a fase S é a fase da síntese durante a qual o DN A é sintetizado (duplicado).

Iv Proto-oncogenes são estruturas normais do DN A suscetíveis de modificações introduzidas por diversos mecanismos (mutações, inserção viral), transformando-se em oncogenes, ou seja, genes capazes de ativar a atividade de divisão celular em condições onde este processo não deveria ocorrer. Em determinados momentos ou sob determinadas condições eles se ativam e provocam a transformação destas células, levando a um crescimento desmedido. Estes oncogenes tem a capacidade de se amplificar dentro do DN A, ou seja, aparecem em grande número de cópias provocando um aumento dos níveis de expressão das proteínas que eles codificam.
} 
que 0 bom prognóstico, conferido pelos valores positivos do $R E$, não é passível de sustentação no longo prazo. Pichon et al. ${ }^{84}$ afirmam que 0 valor preditivo da condição do RE no tumor primário decresce aproximadamente $20 \%$ ao ano, Bernoux et al. ${ }^{96}$ dizem que a significância estatística desaparece aos 10 anos de seguimento. Se por um lado o RE não se apresenta como um preditor competente da sobrevida no longo prazo, por outro ele é um forte preditor de resposta para a terapia endócrina adjuvante, sendo menos efetivo para mulheres com tumores receptor hormonal negativo, principalmente naquelas pacientes com idade inferior a 50 anos. ${ }^{11}$

Thorpe et al., ${ }^{88}$ estudando pacientes em pós-menopausa, concluem que enquanto os altos níveis de RE (acima de $108 \mathrm{fmol} / \mathrm{mg}$ ) predispõem a um pobre prognóstico; é precisamente este grupo que experimenta um grande benefício com o uso adjuntivo da terapia hormonal.

A combinação da condição do RE e RP é definida por Bernoux et al. ${ }^{96}$ como um grupo com especificidades clínicas e biológicas, que pode ser considerado específico para tratamento endócrino. Já Robertson et al., ${ }^{97}$ trabalhando com pacientes submetidos a hormonioterapia, dizem que a combinação do RE e RP possibilita um predição mais acurada dos resultados clínicos mas não ajuda na seleção individual dos pacientes para terapia endócrina. Em pacientes com doença metastática tratada com hormônio, ${ }^{98}$ observou-se que 0 aumento de resposta foi relacionado ao acometimento do tecido conjuntivo e RP positivo. Os pacientes mais idosos e com um só sítio de metástase com RP positivo apresentaram o maior tempo de intervalo livre até a progressão da doença.

Com relação ao tratamento quimioterápico, M iles et al., ${ }^{79} \mathrm{em}$ um estudo randomizado (quimioterapia adjuntiva $x$ sem quimioterapia adjuntiva), observaram que os melhores ben eficiados foram os pacientes $R E$ negativos, que apresentaram uma sobrevida média 5 vezes maior (11,6 anos e 2 anos) para os que receberam quimioterapia, enquanto para os pacientes RE-positivos, a média foi de 11,3 contra 7,7 anos Já
Vollenweider-Z eraargui et al. ${ }^{95}$ não vêem valor na predição da resposta a quimioterapia.

\section{CONCLUSÕES}

Entre os inúmeros fatores prognóstico ainda temos dois daqueles considerados clássicos, o tamanho do tumor e a condição dos linfonodos axilares, os dois mais importantes indicadores prognósticos para 0 câncer de mama. 0 tamanho do tumor no momento do diagnóstico éfator determinante na indicação do tratamento conservador, além de se constituir ainda, nos casos de pacientes com ausência de comprometimento metastático dos linfonodos, no melhor preditor de recidiva da doença. $\mathrm{Q}$ uanto maior o tamanho do tumor, maiores são as chances da existência de comprometimento metastático dos linfonodos loco-regionais. 0 conhecimento da condição dos linfonodos axilares ainda se constitui na mais importante das informações prognósticas, porém a determinação do nível anatômico dos linfonodos envolvidos pela metástase não se constitui num elemento independente, sendo o risco dos comprometimento diretamente proporcional ao tamanho do tumor e independente do nível.

Q uanto ao tipo histológico, são os tumores do tipo carcinoma tubular e carcinoma medular aqueles que apresentam 0 melhor prognóstico. 0 carcinoma tubular apresenta excelente prognóstico, mesmo nos pacientes com linfonodo axilar positivo, estando a sobrevida desses pacientes muito próximas daquela verificada na população geral, com sobrevida livre de doença em 10 anos superior a $95 \%$.

0 grau histológico reflete o potencial de malignidade do tumor indicando a sua maior ou menor capacidade de metastatização. Q uando usado em conjunção com o estádio da doença, pode melhorar a predição do resultado

0 nível sócio econômico reflete no prognóstico a conseqüência das dificuldades de acesso aos programas de prevenção e aos cuidados médicos que as classes sociais menos favorecidas encontram mesmo nos países mais desenvolvidos, sendo 0 diagnóstico 
estabelecido numa fase já avançada da doença.

Em relação à idade, o pior prognóstico está reservado, ao grupo de mulheres com idade igual ou inferior a 35 anos e àquelas com mais de 75 anos de idade. A melhor sobrevida é verificada no grupo de mulheres com idade entre 45 e 49 anos, podendo 0 estadiamento clínico ser um fator de tendenciosidade se levarmos em consideração que na média esse grupo de mulheres tem 0 diagnóstico estabelecido mais precocemente que naquelas dos demais grupo etários.

A avaliação da angiogênese peritumoral traduz a possi bilidade de metástases a distância por via hematogênica, e pode possibilitar a seleção de pacientes, com câncer inicial de mama, que necessitariam de um tratamento mais agressivo.

A catepsina D e o p53 se apresentam como marcadores prognósticos potencialmente promissores, para os quais melhores definições precisam ser aportadas mais adiante.

A análise da ploidia do DNA não é um indicador significativo de prognóstico e a micrometástase em medula óssea pode ser um preditor útil para pacientes com doença em estádio iniciais, podendo ter influência em estratégias terapêuticas futuras.

A expressão aumentada do c-erbB-2, que ocorre em aproximadamente $20 \%$ de todos os cânceres de mama, se configura como um bom preditor de mau prognóstico. As pacientes c-erbB-2 positivo apresentam alto risco de recidiva precoce e uma menor sobrevida que aquelas com o oncogene negativo. oferecendo nos casos de pacientes linfonodo axilar negativas uma importante informação prognóstica. Com relação ao papel do c-erbB-2 como preditor de resposta terapêutica, este ainda é muito controverso embora seja possível que os pacientes c-erbB2 positivos apresentem uma maior resistência às drogas quimioterápicas.

O conhecimento da condição dos receptores hormonais, em especial o receptor de estrogênio, já tem o seu papel assegurado como um importante elemento na avaliação clínica pós diagnóstico do câncer de mama. Tem se observado de forma consistente que os pacientes com tumores $\mathrm{RH}$ positivos tendem a apresentar uma sobrevida maior que àqueles pacientes com tumores $\mathrm{RH}$ negativos, e que também, a identificação de subpopulações com características desfavoráveis possibilita uma maior atenção terapêutica com uma conseqüente melhoria na sobrevida geral ou no sobrevida livre de doença. Por outro lado, o bom prognóstico conferido aos pacientes, pel os val ores positivos do $R E$, não é sustentável no longo prazo, desaparecendo aos 10 anos de seguimento. Segue, portanto, sendo um preditor competente de resposta para a terapia hormonal adjuvante, a qual é menos efetiva nas mulheres RH negativa, mas não apresenta bons resultados como preditor de resposta à quimioterapia.

\section{REFERÊNCIAS BIBLIOGRÁFICAS}

1. Instituto $\mathrm{N}$ acional de $\mathrm{C}$ âncer (Brasil). Estimativas 2000 deincidênciae mortalidade por câncer no Brasil. Rio deJ aneiro: Instituto $\mathrm{N}$ acional deC âncer; 2000.

2. Kock H A, Peixoto JE, N evesALE. Análiseda infra-estruturaparaa mamografia. Radiol Bras 2000;33:23-9.

3. Instituto $\mathrm{N}$ acional deCâncer (Brasil). Produção ambulatorial do SUS. D atasus 1999. Disponível em: http://www.datasus.gov.br.

4. Basset M T, Krieger N. Social class and blackwhite differencesin breast cancer survival. Am J Public H ealth 1986;76:1400-3.

5. Karjalainen S, PukkalaE. Social class asa prognostic factor in breast cancer survival. C ancer 1990;66:819-26.

6. WellsBL, H orm JW. Stageat diagnosis in breast cancer: race and socioeconomica factors. Am J Public H ealth 1992;82:1383-5.

7. Clark GM . Prognostic and predictivefactors. In: H arris JR, Lippman ME, M orrow M, $\mathrm{H}$ ellman $S$, editors. D iseases of breast. 5th ed. Philadelphia: Lippincott-Raven; 1996. $p$. 461-70.

8. Clark GM . D o wereally need prognostic factorsfor breast cancer? Breast C ancer Res Treat 1994;30:117.

9. D onegan W L. Staging methods, primary treatment options and results In: D onegan WL, SprattJS, editors. C ancer of the breast. 2th ed. Philadelphia: Saunders; 1979. p. 221. 
10. Aaltomaa S, Lipponen P, Eskelinen M . D emographic prognostic factors in breast cancer. Acta O ncol 1992;31:635-40.

11. D hingraK, H ortobagyi GN . C ritical evaluation of prognosticfactors Semin O ncol 1996;23:436-45.

12. Carter $C L$, Allen $C, H$ enson $D E$. Relation of tumor size, lymph nodestatus and survival in 24740 breast cancer cases. Cancer 1989;63:181-7.

13. FarleyTA, Flannery JT. Latestage dianosis of breast cancer in women of lower socioeconomic status: public health implications. AmJ Public H ealth 1989;79:1508-12.

14. Fischer B, Slack N H , Bross IDJ. C ancer of the breast: size of neoplasm and prognosis. Cancer 1969;24:1071-80.

15. H enson DE, Ries L, Freedman M A, C arriaga $M$. Relationship among outcome, stage of disease, and histologic grade for 22.616 cases of breast cancer. C ancer 1991;68:2142-9.

16. Alexieva-Figusch J, Van Putten WL, Blankenstein M A, D er W ijst J, Klijn JG. The prognostic value and relationships of patient characteristics, estrogen and progestin receptors, and site of relapse in primary breast cancer. Cancer 1988;61:758-68.

17. Barth RJ, D anforth D N, Venzon DJ, StrausKL, d'Angelo T. M erino MJ, et al. Level of axillary involvement by lymph node metastases from breast cancer isnot an independent predictor of survival. Arch Surg 1991;126:574-7.

18. Salvadori B, G reco M, ClementeC, D eL ellis $\mathrm{R}, \mathrm{D}$ elledonneV, G alluzo D, et al. Prognostic factors in operable breast cancer. Tumori 1983;69:477-84.

19. Korzeniowski S, D ybaT, Skolyszewski J. Clas sical prognostic factors for survival and locoregional control in breast cancer patientstreated with radical mastectomy alone. Acta 0 ncol 1994;33:759-65.

20. Aaltomaa S, Lipponen P, Eskelinen M , Kosma VM , M arin S, AlhavaE, et al. Prognostic scores combining clinical, histological andamorphometric variables in assessment of the disease outcomein female breast cancer. Int J C ancer 1991;49:886-92

21. Balslev I, Axelsson CK, Zedeler K, Rasmussen $B B, C$ arstensen $B$, M ouridsen $H T$. The N ottingham prognostic index applied to 9149 patientsfrom the studies of the $D$ anish Breast $C$ ancer $C$ ooperative G roup. $C$ ancer ResT reat 1994;30:117-26.

22. $\mathrm{H}$ aybittleJ L, Blamey RW, Elston CW, Johnson
J, D oylePJ, Campbel FC, et al. A prognostic index in primary breast cancer. $\mathrm{Br} J \mathrm{C}$ ancer 1982;45:361-6.

23. Palmer M K, LythgoeJP, Smith A. Prognostic factors in breast cancer. Br J Surg 1982;69:697-8

24. Valagussa P, Bonadonna G, Veronesi U. Patterns of relapse and survival following radical mastectomy. C ancer 1978;41:1170-8.

25. Rosen PP, Groshen S, Saigo PE, Kinne DW, $\mathrm{H}$ ellman S. Pathological prognostic factorsin stage I (T IN OM 0) and stage II (T IN IM O) breast carcinoma: astudy of 644 patients with median follow-up of 18 years. J Clin O ncol 1989;7:1239-45.

26. FracchiaAA, Robinson D , Legaspi A, G reenall MJ, KinneD W, Groshen S. Survival in bilateral breast cancer. Cancer 1985;55:1414-21.

27. Fentiman IS, H yland D, C haudary M A, G re gory W M . Prognosis of pacients with breast cancer up to $1 \mathrm{~cm}$ in diameter. Eur J Cancer 1996;32A:417-20.

28. Adair F, Berg J, Joubert L, Robbins GF. Longterm follow-up of breast cancer patients: the 30 year report. C ancer 1974;33:1145-50.

29. Ketterhagen JP, Q uakenbush SR, $H$ aushalter RA. Tumor histology as a prognostic determinant in carcinoma of the breast. Surg $G$ ynecol O bstet 1984;158:120-3.

30. D iab SG, Clark GM , 0 sborne CK, Libby A, Allred D C, ElledgeM . Tumor characteristicsand clinical outcome of tubular and mucinousbreast carcinomas. J Clin O ncol 1999;17:1442-8.

31. Reinfuss M , Stelmach A, M itus], Rys ], D uda K. Typical medullary carcinoma of thebreast: a clinical and pathological analysis of 52 cases. J Surg O ncol 1995;60:89-94.

32. BurkeH B, H enson DE. H istologic gradeas a prognostic factor in breast carcinoma. $\mathrm{C}$ ancer 1997;80:1703-5.

33. R oberti N E. The role of histologic grading in theprognosis of patientswith carcinoma of the breast. Cancer 1997;80:1708-16.

34. Elston CW, EllisIO . Pathological prognostic factors in breast cancer. I. The value of histological gradein breast cancer: experiencefrom a large study with long-term follow-up. $\mathrm{H}$ istopathology 1991;19:403-10.

35. $\mathrm{H}$ ost $\mathrm{H}$, Lund E. Ageas a prognostic factor in breast cancer. C ancer 1986;57:2217-21.

36. Kroman $N$, Jensen $M$, Wohlfahrt J, M ouridsen $H T$, Andersen PK, M elbye M. Factors influencing the effect of age on prognosisin breast 
cancer: population based study. BM J 2000;320:474-9.

37. Peer PGM, Verbeek ALM, M ravunac $M$, $\mathrm{H}$ endriks JH CL, $\mathrm{H}$ olland R. Prognosis of younger and older patients with early breast cancer. Br J Cancer 1996;73:382-5.

38. Santi M, C apocacciaR, VerdecchiaA, EsteveJ, Gatta G, M icheli A, et al. Survival of women with breast cancer in Europe: variation with age, year of diagnosisand country. Int J Cancer 1998;77:679-83.

39. Adami H O, M alker BM , H olmberg L, Persson I, Stone B. The relation between survival and ageat diagnosisin breast cancer. N Engl J M ed 1986;315:559-63.

40. Bonnier P, Romain S, Charpin C, LejeuneC, Tubiana N, M artin N , et al. Ageasa prognostic factor in breast cancer relationship to pathologic and biologic features. Int J Cancer 1995;62:138-44.

41. A ceñero M JF, G onzález JF, G allego M G, BallesterosA. Vascular enumeration asasignificant prognosticator for invasive breast carcinoma. J Clin O ncol 1998;16:1684-8.

42. Weidner $N$, SempleJ P, Welch W R, Folkman J. Tumor angiogenesisand metastasis - correlation in invasivebreast carcinoma. $\mathrm{N}$ Engl J M ed 1991;324:1-8.

43. Weidner N , Folkman J, Pozza F, Bevilacqua P, Allred EN , M oore D H , et al. Tumor angiogenesis: a new significant and independent prognostic indicator in early-stage breast carcinoma. J N atl C ancer Inst 1992;84:11875-87.

44. $N$ arita $M, N$ akao $K, O$ gino $N, N$ akahara $M$, $O$ nishi $A$, Tsujimoto $M$. Independent prognostic factors in breast cancer patients. Am J Surg 1998;175:73-5.

45. H eimann $R$, Ferguson $D$, Powers $C$, Recant W M , Weichselbaum RR, H ellman S. Angiogenesis as a predictor of long-term survival for patients with nodenegativebreast cancer.J $\mathrm{N}$ atl Cancer Inst 1996;88:1764-9.

46. Ravdin PM . Evaluation of cathepsin D as a prognostic factor in breast cancer. B reast $C$ ancer ResTreat 1993;24:219-26.

47. Tetu B, Brisson J, CoteC, Brisson S, Poatvin D, RobergeN . Prognostic significance of cathepsin-D expression in node positive breast carcinoma: an immunohistochemical study. Int J Cancer 1993;55:429-35.

48. Charpin C, Garcia S, Bouvier C, M artini F, Lavaut M, Allasia C, et al. Cathepsin D de tected by automated and quantitativeimmu- nohistochemistry in breast carcinomas: correlation with overal and diseasefreesurvival. J Clin Pathol 1997;50:586-90.

49. Billgren $A M$, Rutqvist $L E$, Johansson $H$, $H$ agerstrom T, Skoog L. Therole of cahepsin D and PAI- 1 in primary invasive breast cancer as prognosticators and predictors of treatment benefit with adjuvant tamoxifen. Eur J Cancer 2000;36:1374-80.

50. Keyhani-R ofaghaS, O 'Toole RV, Farrar W B, Sickle-Santanello B, D eC enzo J, Young D. Is D N A ploidy an independent prognostic indicator in infiltrativenode-negativebreast adenocarcinoma? C ancer 1990;65:1577-82.

51. CuferT, Lamovec J, Bracko M , Lindtner J, UsK rasovec M . Prognostic value of D N A ploidy in breast cancer stage I-II. N eoplasma 1997;44:127-32.

52. H ou M F, H uang TJ, H uang $C J$, H uang $Y S$, $\mathrm{H}$ sieh JS, Lin SJ. Expression of p53 protein and it's prognostic significancein breast cancer patients. $\mathrm{KaO} \mathrm{H}$ siung I H sueh $\mathrm{Ko} \mathrm{H}$ sueh Tsa Chih 1996;12:471-8.

53. Patel DD, Bhatavdekar JM, Chikhlikar PR, G hosh N, Suthar TP, Shah N G, et al. N ode negative breast carcinoma: hyperprolactinemia and/or overexpression of p53 as an independent predictor of poor prognosis compared to newer and established prognosticators. J Surg O ncol 1996;62:86-92.

54. Poller D N , Snead D R, RobertsEC, Galea M, Bell JA, Gilmour A, et al. 0 strogen recetor expression in ductal carcinoma in situ of the breast: relationship to flow cytometric analysis of DNA and expression of the c-erbB-2 oncoprotein. Br J Cancer 1993;68:156-61.

55. M ansi JL, Easton D, Berger U, G azet J C, Ford $H T$, D earaley $D$, et al. Bone marrow micrometastases in primary breast cancer: prognostic significance after 6 yearsfollow-up. Eur J Cancer 1991;27:1552-5.

56. D iel IJ, Kaufmann M , C ostaSD , H olleR, von $M$ inckwitz G, Solomayer EF, et al. $M$ icrometastases breast cancer cells in bone marrow at primary surgery: prognostic valuein comparison with nodal status. J $\mathrm{N}$ atl $\mathrm{C}$ ancer Inst 1996;88:1652-8.

57. M olino A, Pelosi G, Turazza M, Sperotto L, Bonetti $A, N$ ortilli $R$, et al. Bone marrow micrometastases in 109 breast cancer pacients: correlations with clinical and pathological features and prognosis. Breast $C$ ancer Res Treat 1997;42:23-30. 
58. M olino A, Pelosi G, M icciolo R, Turazza M, N ortilli $R$, Pavanel $F$, et al. Bone marrow micrometastases in breast cancer pacients. Breast Cancer ResTreat 1999;58:123-30.

59. Landys K, Persson S, Kovarik J, H ultborn R, $\mathrm{H}$ olmberg $\mathrm{E}$. Prognostic value of bonemarrow biopsy in operablebreast cancer patientsat the time of initial diagnosis: results of a 20-year median follow-up. Breast Cancer Res Treat 1998:49:27-33.

60. Braun S, Paltel K. Prognostic significance of micrometastases in bonemarrow involvement. Breast C ancer ResTreat 1998; 52:201-16.

61.J anni W, Gastroph S, H epp F, Kentenich C, Rjosk D, Shindlbeck C, et al. Prognostic significance of an increased number of micrometastasestumor cells in the bone marrow of patients with first recurrence of breast carcinoma. C ancer 2000;88:2252-9.

62. Slamon DJ, Clark GM, Wong SG, Levin WJ, Ullrich A, M cG uireW L. H uman breast cancer: correlation of relapse and survival with amplification of the H ER-2/neu oncongene. Science 1987;235:177-82.

63. D e Potter $C R$, Schelfhout AM . Theneu protein and breast cancer. Virchows Arch 1995;426:107-15.

64. Alred D C, Clark GM , Tandon AK, M olina R, Tormey D C, O sborneCK, et al. Her-2/neu in node negative breast cancer: prognostic significance of overexpression influenced by thepresence of in situ carcinoma. J Clin O ncol 1992;10(4):599-605.

65. M olinaR, CioccaD R, Tandon AK, Allred DC, Clark GM , Chamness GC, et al. Expression of $\mathrm{H}$ er-2/neu oncoprotein in human breast cancer. A comparison of immunohistochemical and western blot techniques. Anticancer Res 1992;12:1965-72.

66. Scorilas A, TrangasT, Yotis], Pateras C, Talieri $M$. D etermination of c-myc amplification and overexpression in breast cancer patients: evaluation of its prognostic valueagainst c-erbB-2, cathepsin-D and clinicopathological characteristics using univariate and multivariate analysis. Br J C ancer 1999;81:1385-91.

67. M CC ann AH , D ervan PA, O 'Regan M, C odd M B, G ullick W J, Tobin BM J, et al. Prognostic significance of $C$-erbB-2 and estrogen receptor status in human breast cancer. Cancer Res 1991;51:3296-303.

68.Gasparini G, Gullick WJ, Bevilacqua P, Sainsbury JRC, M eli Salvatore, Baracchi P, et al. H uman breast cancer: prognostic signifi- cance of the c-erbB-2 oncoprotein compared with epidermal growth factor receptor, D N A ploidy, and conventioanl pathologic features. J Clin O ncol 1992;10:686-95.

69. Gullick WJ, LoveSB, Wright C, Barnes D M , G usterson B, H arrisAL, et al. c-erbB-2 protein overexpression in breast cancer isa risk factor in patients with involved and uninvolved lymph nodes. Br J C ancer 1991;63:434-8.

70. H origuchi J, Lino Y, M orishita Y. Prognostic significance of c-erbB-2 expression in invasive ductal carcinoma of breast. Jpn J Clin O ncol 1995;25:119-23.

71. Jakic-Razumovic), Petrovecki M , U zarevic B, G amulin S. M utual predictive value of c-erbB2 overexpression and various prognostic factorsin ductal invasivebreast carcinoma. Tumori 2000;86:30-6.

72. Thomas $M$, N oguchi M , Fonseca L, Kitagawa $\mathrm{H}$, Kinoshita K, M iyazaki. Prognostic significance of $\mathrm{H}$ elix pomatia lectin and c-erbB-2 oncoprotein in human breast cancer. $\mathrm{Br} J \mathrm{C}$ ancer 1993;68:621-6.

73. Wright $C$, Angus $B, N$ icholson S, Sainsbury RC, Cairns], Gullick WJ, et al. Expression of cerbB-2 oncoprotein: a prognostic indicator in human breast cancer. Cancer Res 1989;49:2087-90.

74. Ioachim E, KaminaS, Athanassiadou S, Agnantis $\mathrm{N}$ ). The prognostic significance of epidermal growth factor receptor (EGFR), c-erbB-2, Ki67 and PCN A expression in breast cancer. Anticancer Res 1996;16:3141-7.

75. M erchant WJ, M illis RR, Smith P, Chaudary $M$ A, Barnes D M . Expression of c-erbB-2 and p53 protein is similar in breast cancer from british and japanese women. Int J Cancer 1999;84:278-83.

76. N oguchi M , Koyassaki N , O hta N , Kitagawa $H$, Earashi $M$, Thomas $M$, et al. c-erbB-2 oncoprotein expression versus internal mammary lymph nodemetastasesas additional prognostic factors in patients with axillary lymph node-positive breast cancer. Cancer 1992;69:2953-60.

77. N oguchi M, O htaN , Thomas M , KitagawaH , Earashi M, M iyazaki I, et al. A retrospective study on the clinical and biological prediction of axillary lymph nodemetastasisin breast cancer. J pn J Surg 1993;23:573-9.

78. K eshgegian AA. c-erbB-2 oncoprotein overexpression in breast carcinoma: inversecorrelation with biochemically and immunohistochemically-determined hormone 
receptors. Breast Cancer Res Treat 1995;35:201-10.

79. M iles DW, $H$ arris W H, Gillet CE, Smith $P$, Barnes D M . Effect of $c$-erbB-2 and estrogen receptor status on survival of women with primary breast cancer treated with adjuvant cyclophosphamide/methotrexate/fluorouracil. Int J Cancer 1999;84:354-9.

80. Tetu $B, B$ risson J. Prognostic significance of HER-2/neu oncoprotein expression in node positive breast cancer. Theinfluence of pattern of immunostaining and adjuvant therapy. $C$ ancer 1994;73:2359-65.

81. AlbertsSR, IngleJN, RochePR, ChaSS, Wold LE, Farr G H Jr, et al. Comparison of estrogen receptor determinations by a biochemical ligand-binding assay and immunohistochemical staining with monoclonal antibody ER1D 5 in females with lymph node positivebreast carcinoma entered on two prospectiveclinical trials. C ancer 1996;78:764-72.

82. Esteban JM, Ahn C, Battifora H, Felder B. $Q$ uantitativeimmunohistochemical assay for hormonal receptors: technical aspectsand biological significance. J Cell Biochem 1994;19 Suppl:138-45.

83. H upperets PS, Volovies L, Schouten LJ, Jager $\mathrm{JJ}$, Shouten H C, H illen H F, et al. Theprognostic significance of steroid receptor activity in tumor tissues of patients with primary breast cancer. Am J Clin Oncol 1997;20:546-51.

84. Pichon M F, Broet $P, M$ agdelenat $H, D$ elarue JC, Spyratos F, Basuyau JP, et al. Prognostic value of steroid receptors after long-term follow-up of 2257 operable breast cancers. $\mathrm{Br}$ J Cancer 1996;73:1545-51.

85. H ähnell R, WoodingsT, V ivian AB. Prognostic value of estrogen receptor in primary breast cancer. Cancer 1979;44:671-5.

86. Bonnier P, Romain S, Giacalone PL, Laffargue F, M artin PM , Piana L. Clinical and biologic prognostic factors in breast cancer diagnosed during postmenopausal hormonereplacement therapy. $O$ bstet Gynecol 1995;85:11-7.

87. Saimura M , Fukutomi T, Tsuda H , Sato H , M iyamoto K, Akashi-Tanaka S, et al. Prognosis of a series of 763 consecutive nodenegative invasive breast cancer patients without adjuvant therapy: analysis of clincopathological prognostic factor. J Surg Oncol 1999;71:101-5.

88. Thorpe SM , Christensen IJ, Rasmussen BB, Rose C. Short recurrence freesurvival associated with high estrogen receptor levels in the natural history of postmenopausal, primary breast cancer. Eur J C ancer 1993,29A:971-7.

89. Ruder AM , Lubin F, Wax Y, G eier A, Alfundary E, C hetrit A. Estrogen and progesteronereceptor in breast cancer patients. E pidemiologic characteristics and survival differences. $C$ ancer 1989;64:196-202.

90. Kinsel LB, Szabo E, Greene GL, Konrath J, Leight G S, M cC arty KS. Immunocytochemical analysis of estrogen receptor as a predictor of prognosisin breast cancer patients: comparison with quantitative biochemical methods. C ancer Res 1989;49:1052-6.

91. Clark GM, Wenger CR, Beardslee $S$, $O$ wens $M$ A, Pounds G, Oldaker T, et al. H ow to integrate steroid hormone receptor, flow cytometric, and other prognostic information in regard to primary breast cancer. $C$ ancer 1993;71:2157-62.

92. InsaA, Lluch A, Prosper F, M arugan I, M artinezArgullo A, Garcia-Conde J. Prognostic factors preditingsurvival from first recurrencein patients with metastatic breast cancer: analysis of 439 patients. Breast Cancer ResTreat 1999;56:67-78.

93. H awkinsRA, TesdaleAL, Killen M E, Jack WJL, Chetty U, D ixon JM , et al. Prospectiveevaluation of prognosticfactorsin operablebreast cancer. BrJ C ancer 1996;74:1469-78.

94. Pichon M F, Pallud C, H aceneK, M ilgrom E. Prognostic valule of progesteronereceptor after long-term follow-up in primary breast cancer. Eur J Cancer 1992; 28A:1676-80.

95. Vollenweider-Zerargui $L, B$ arrelet $L$, Wong $Y$, Lemarchand-Beraud T, Gomez F. The predictive value of estrogen and progesterone receptors' concentrations on the clinical behavior of breast cancer in women. Clinical correlation on 547 patients. Cancer 1986;57(6):1171-80.

96. Bernoux A, de Cremoux $P$, Laine-Bidron $C$, $M$ artin EC, Asselain B, M agdelenat H . Estrogen receptor negative and progesterone receptor positive primary breast cancer; pathological characteristics and clinical outcome. Institut C urieBreast Cancer Study G roup. Breast C ancer ResTreat 1998;49:219-25.

97. RobertsonJF, Cannon PM , Nicholson RI, Blamey RW. O estrogen and progesterone receptors as prognostic variables in hormonally treated breast cancer. IntJ Biol M arkers 1996;11:29-35.

98. KussJT, M uss H B, H oen H, C aseD . Tamoxifen isinitial endocrinetherapy for metastatic breast cancer: long term follow-up of two Piedmont O ncology Association (POA) trials. Breast C ancer ResTreat 1997;42:265-74. 